\title{
Correction to: G2A Communication Channel Modeling and Characterization Using Confocal Prolates
}

\author{
Muhammad-Yasir Masood Mirza ${ }^{1}$ (D) $\cdot$ Noor M. Khan ${ }^{1}$
}

Published online: 3 August 2020

(c) Springer Science+Business Media, LLC, part of Springer Nature 2020

\section{Correction to: Wireless Personal Communications https://doi.org/10.1007/s11277-020-07597-4}

The original publication contains the following errors:

1. In Eq. 31 and in Eq. 32 before the plus sign, $\mathrm{GA}_{1}$ should have read $\mathrm{GA}_{0}$.

2. In section 5.3, microseconds ( $\mu \mathrm{sec}$ ) and $\mathrm{MHz}$ were mistakenly used instead of milliseconds (ms) and kHz, resp.

Publisher's Note Springer Nature remains neutral with regard to jurisdictional claims in published maps and institutional affiliations.

The original article can be found online at https://doi.org/10.1007/s11277-020-07597-4.

Muhammad-Yasir Masood Mirza mmymasood@gmail.com

Noor M. Khan

noor@ieee.org

1 Acme Center for Research in Wireless Communications (ARWiC), Department of Electrical Engineering, Capital University of Science and Technology, Kahuta Road, Zone-V,

Islamabad 44000, Pakistan 